\title{
Cardiovascular effects of edible oils: a comparison between four popular edible oils
}

\author{
D. Bester, A. J. Esterhuyse, E. J. Truter and J. van Rooyen* \\ Department of Biomedical Sciences, Faculty of Health and Wellness Sciences, \\ Cape Peninsula University of Technology, Bellville, South Africa
}

\begin{abstract}
Edible oils form an essential part of the modern diet. These oils play a role as an energy source, and provide the diet with many beneficial micronutrients. Although a popular conception may be that fat should be avoided, certain edible oils as a dietary supplement may play an important role in the improvement of cardiovascular health. CVD has become one of the leading causes of death worldwide. Dietary supplementation with different oils may have beneficial effects on cardiovascular health. While olive oil and sunflower-seed oil are known to reduce serum cholesterol, fish oil has become well known for reducing potentially fatal cardiac arrhythmias. Recently, red palm oil research has shown beneficial effects on cardiac recovery from ischaemiareperfusion injury. It is clear that dietary supplementation with edible oils may play a vital role in reducing the mortality rate due to heart disease. The specific benefits and disadvantages of these oils should, however, be explored in greater depth. The present review will attempt to identify the benefits and shortcomings of four popular edible oils, namely olive oil, sunflower-seed oil, fish oil and palm oil. Additionally the present review will aim to reveal potential areas of research which could further enhance our understanding of the effects of edible oils on cardiovascular health.
\end{abstract}

Olive oil: Sunflower-seed oil: Fish oil: Palm oil: Red palm oil: Heart: Cardiovascular effects

\section{Introduction}

In the last decade or two, research on the consumption of dietary fats and oils has become an important topic. High fat content, together with the type of fat in the diet, has been blamed for causing conditions such as obesity, insulin resistance and metabolic syndrome $\mathrm{X}$. Therefore, lifethreatening conditions such as stroke and acute myocardial infarction can be directly related to either the fat content or fat type in the diet ${ }^{(1-4)}$. However, the inclusion of oils and fats in the diet is necessary, as the lack thereof could lead to other potentially life-shortening disorders, such as glomerulonephritis, hypertension, diabetes mellitus, metabolic syndrome X, psoriasis, Alzheimer's disease, schizophrenia, depression, CHD, atherosclerosis and cancer ${ }^{(5-10)}$. The above-mentioned diseases are not only a result of decreased fat intake, but also due to a shortage of fat-soluble vitamins and essential fatty acids that are normally contained in oils and fats.

Many studies have been done on edible oils and their effects on cardiovascular health. However, few of these studies compared the effects of more than two of these oils with each other. There also seem to be considerable gaps in the literature concerning certain areas of cardiovascular health with respect to many oils. The need to revisit the literature has thus arisen.

Heart disease is still one of the major causes of mortality in the developed world ${ }^{(11,12)}$. The National Cholesterol Education Program has recommended that a reduction in LDL-cholesterol (LDL) should be used as a treatment of choice for heart disease and that increased LDL-cholesterol be used for the early detection of potential heart disease ${ }^{(13)}$. Previous studies have shown that increased TAG may also be considered to be a risk factor for the development of heart disease $\mathrm{e}^{(14-17)}$. Research has also shown that the attenuation of inflammation may offer protection against ischaemia-reperfusion injury ${ }^{(18-21)}$. Carnieto et al. ${ }^{(21)}$ demonstrated in an in vivo dog model that a reduced cyclo-oxygenase-2-related inflammatory response was able to limit tissue damage associated with ischaemiareperfusion injury. Cyclo-oxygenase- 2 is an enzyme that is responsible for converting non-esterified arachidonic acid to pro-inflammatory prostaglandins. These authors conclude that a cyclo-oxygenase- 2 inhibitor may offer some protection against a myocardial ischaemia-reperfusion injury.

\footnotetext{
Abbreviations: HMG-CoA, 3-hydroxy-3-methylglutaryl-coenzyme A; PKB, protein kinase B; ROS, reactive oxygen species; RPO, red palm oil; SFO, sunflower-seed oil; TRF, tocotrienol-rich fraction.

* Corresponding author: Professor J. van Rooyen, email vanrooyenj@cput.ac.za
} 
Apart from their fatty acid content, oils also provide a variety of micronutrients that may have beneficial effects on, amongst others, the cardiovascular system. Both the fatty acid component and micronutrient component of an oil may influence cardiovascular health. Researchers often focus on a particular component of a product and call it the 'active ingredient'. In the case of natural products, the oil may be viewed as a cocktail of active ingredients that often have a synergistic effect on health ${ }^{(22-27)}$ (see Table 1).

Better understanding of the physiological control, mechanisms of lipid metabolism and the associated risk factors for heart disease and stroke has increased markedly via research carried out in recent times. Many of these studies have shown that fatty acids and combinations of fatty acids are beneficial to cardiovascular health ${ }^{(1,8,20,21)}$.

The present review will focus on the beneficial effects of dietary edible oils and fat on the cardiovascular system. We will focus on four well-known oils, namely olive oil, sunflower-seed oil (SFO), fish oil and palm oil.

\section{Olive oil \\ Refining of olive oil}

Olive oil is a rich tasty oil produced from the fruit of Olea europaea which grows naturally in the Mediterranean region. This oil is produced from olives by: (1) washing, (2) crushing, (3) kneading and (4) centrifugation of olives ${ }^{(28,29)}$. When the $\mathrm{pH}$ of the olive oil is below $3 \cdot 3$, the oil is refined to produce a common olive oil ${ }^{(28)}$. Refining of olive pomace (a crude oil produced by centrifugation of olives in water) can take place through secondary physical extraction and centrifugation or chemical refining ${ }^{(29)}$. Unrefined olive oil is known as virgin olive oil and may be viewed as unique among oils as it is produced without refining. Various grades of olive oil are commercially available, depending on how it was refined. Virgin olive oil should be considered the healthiest, as no refining takes place. This leads to the optimal retention of micronutrients, which are destroyed through chemical refining. Olive oil has a rich medical history and has traditionally been used to treat colic, alopecia, paralysis, rheumatic pain, sciatica and hypertension $^{(30)}$.

\section{Composition of olive oil}

Olive oil is a yellow-coloured oil that consists of mainly MUFA, of which oleic acid comprises $72-79 \%(28,31,32)$. In comparison with PUFA, MUFA are less susceptible to oxidation. This in turn leads to increased availability of antioxidants in the active form and better stability of olive $\mathrm{oil}^{(3,28,33-37)}$.

Olive oil also contains some antioxidant micronutrients, namely polyphenols and squalene ${ }^{(28,31,32,38,39)}$. More than $80 \%$ of the olive oil phenolic compounds are lost during the refinery process. Therefore, the phenolic compound content of virgin olive oil (about $230 \mathrm{mg} / \mathrm{kg}$, common range $130-350 \mathrm{mg} / \mathrm{kg}$ ) is higher than that in common olive oil $^{(28,40)}$. However, in another study Owen et al. ${ }^{(28)}$ found that the total phenolic content of olive oil may be as high as $500 \mathrm{mg} / \mathrm{kg}$. The major phenols are tyrosol, hydroxytyrosol, oleuropein and ligstroside ${ }^{(28,39,41)}$. Of these polyphenols, tyrosol and hydroxytyrosol are the most abundant and represent $30 \%$ of the total polyphenol content of olive $\mathrm{oil}^{(28)}$. Formation of tyrosol and hydroxytyrosol takes place through the hydrolysis of oleuropein and ligstroside during storage of the olive oil ${ }^{(42)}$. Tyrosol, hydroxytyrosol and oleuropein all contain a catechol group, which has been shown to have antioxidant activity ${ }^{(28,39,43,44)}$. Research has shown that hydroxytyrosol and oleuropein are the most effective antioxidants in olive oil and may exert better antioxidant activity than vitamin $\mathrm{E}^{(28,41)}$.

Olive oil is considered to be extremely rich in squalene and contains approximately $0.7 \%$ of this hydrocarbon ${ }^{(28,31)}$. Other foods and oils may contain squalene at a level between 0.002 and $0.03 \%$. Squalene is an antioxidant by virtue of its ability to quench singlet oxygen radicals, and inhibits cholesterol synthesis through 3-hydroxy-3-methylglutaryl-coenzyme A (HMG-CoA) reductase inhibition $^{(31,45)}$. Apart from the inhibition of HMG-CoA reductase by olive oil, its fatty acid composition may play a role in improving the serum lipid profile. This, however, has not been proven conclusively ${ }^{(46)}$.

Table 1. Summary of the content of the oils reviewed

\begin{tabular}{|c|c|c|c|c|c|}
\hline Content & Olive oil & Sunflower-seed oil & Fish oil & Palm oil & Red palm oil \\
\hline Total SFA (\%) & $10 \cdot 9$ & - & $2 \cdot 6$ & 51 & 51 \\
\hline Total MUFA (\%) & $79 \cdot 8$ & - & $9 \cdot 4$ & $44 \cdot 3$ & 38 \\
\hline Total PUFA (\%) & $9 \cdot 3$ & $60-75$ & $81 \cdot 8$ & 3.7 & 11 \\
\hline Stearic acid (\%) & $3 \cdot 4$ & - & $1 \cdot 2$ & 3.84 & 5 \\
\hline Palmitic acid (\%) & $10 \cdot 1$ & - & 0.9 & $39 \cdot 15$ & 44 \\
\hline Oleic acid (\%) & $72-78.9$ & - & $3 \cdot 8$ & $43 \cdot 62$ & 38 \\
\hline Linoleic acid (\%) & $5 \cdot 7$ & $60-70$ & $1 \cdot 7$ & $11 \cdot 32$ & 11 \\
\hline EPA (\%) & - & - & $32 \cdot 2$ & - & - \\
\hline DHA (\%) & - & - & $31 \cdot 2$ & - & - \\
\hline Vitamin E (ppm) & - & \pm 500 & - & $62 \mathrm{mg} / \mathrm{kg}$ & $559-1000$ \\
\hline Carotenoids (ppm) & - & - & - & $1.2 \mathrm{mg} / \mathrm{kg}$ & 500 \\
\hline Polyphenols (mg/kg) & $230-500$ & - & - & - & - \\
\hline Squaline (\%) & 0.7 & - & - & Trace & $1.1 \dagger$ \\
\hline Co-enzyme Q10 (mg/l) & - & - & - & $0.4^{*}$ & $0.4^{*}$ \\
\hline
\end{tabular}

ppm, Parts per million.

* Indicated value is as found in Carotino Premium palm oil (Carotino Sdn Bhd, Johor Bahru, Malaysia).

† Indicated value is as found in Carotino red palm oil concentrate (Carotino Sdn Bhd, Johor Bahru, Malaysia). 
Other micronutrients within olive oil include lignans, phenyl-ethyl alcohols and secoiridoids ${ }^{(47)}$. These micronutrients have also been credited with antioxidant effects, but not as significant as oleuropein and hydroxytyrosol ${ }^{(47)}$.

\section{Cardiovascular studies with olive oil}

A study by Keys et al. ${ }^{(48)}$ suggested that olive oil consumption decreases the incidence of degenerative diseases such as CHD and cancer. This study used surveys to measure the general diet of a population, and calculate the fat content of the diet. The mortality rate of men between the ages of 40 and 59 years was then monitored over a 15 -year period for these populations. One of the major findings of this study was a negative correlation between MUFA in the diet and death due to CHD.

Antioxidant effects of olive oil. The high content of polyphenols in olive oil suggests that they can be important antioxidants in vivo, although no conclusions can be made as to their effectiveness. One study showed that even when these polyphenol levels were increased in the blood, they failed to protect LDL from oxidation ${ }^{(49)}$. Volunteers in this study consumed both a high- and low-polyphenol diet, respectively, for 3 weeks, with a 2 -week washout period between the two diets. The high-polyphenol diet contained $308 \mathrm{mg}$ polyphenols $/ \mathrm{kg}$, while the low-polyphenol diet contained $43 \mathrm{mg} / \mathrm{kg}$. The mean difference in polyphenol intake between the diets was $18 \mathrm{mg} / \mathrm{d}$. It is possible that the difference in polyphenol content of the diets was too small to achieve significant protection against HDL and LDL oxidation. However, the authors designed the highpolyphenol diet to contain the highest amount of polyphenols that would be possible to consume in a daily diet. A study by Eder et al. ${ }^{(37)}$ investigated the effect of supplementation of edible oils on lipid peroxidation in the liver. Female rats were fed a standard rat chow diet, or a standard rat chow diet plus SFO, rapeseed oil, olive oil or coconut oil for 4 weeks. They found that olive oil neither contributes to lipid peroxidation, nor prevents it and concluded that there is no antioxidative protection offered by olive oil supplementation. However, chemical analysis by Briante et al. ${ }^{(50)}$ has shown that polyphenols present in olive oil may have an antioxidant or pro-oxidant effect. They concluded, first, that low concentrations of olive oil polyphenols (lower than $23 \mu \mathrm{g}$ oleuropein/mg and $18.2 \mu \mathrm{g}$ hydroxytyrosol/mg) have a pro-oxidant effect on LDL, while higher concentrations have an antioxidant effect. Second, they found that metal ions play a major role in LDL oxidation in vivo, and that olive oil polyphenols may reduce $\mathrm{Cu}$ ions and thus prevent LDL oxidation. In a study by Aguilera et al. ${ }^{(51)}$, virgin olive oil was compared with $\alpha$-tocopherol-enriched SFO, and was found to offer better protection against LDL oxidation. Male volunteers with peripheral vascular disease were fed a diet supplemented with olive oil or $\alpha$-tocopherol-enriched SFO for 4 months. In this study the antioxidant content in the blood of the olive oil-supplemented group was found to be lower than that of the SFO group. However, olive oil still offered better protection against oxidative stress, as shown by LDL oxidation. The authors of this study suggested that the high levels of antioxidants in the SFO group could not protect LDL from oxidation due to the oil's high level of unsaturated fat. The results of this study may alternatively argue that the polyphenols in olive oil were more protective than the added $\alpha$-tocopherol in SFO. The fact that the antioxidant content in the blood was also lower in the olive oil-fed group compared with that in the SFO group may suggest that more antioxidants are not necessarily better. These results may thus argue that natural oils are better than artificially manipulated oils.

Hydroxytyrosol and oleuropein have been shown to have a dose-dependent effect by which they can inhibit LDL oxidation ${ }^{(28,44,51)}$. The study by Owen et al. ${ }^{(28)}$ showed these molecules to be more effective antioxidants than vitamin E, dimethyl sulfoxide and butylated hydroxytoluene. Rietjens et al. ${ }^{(52)}$ argued that hydroxytyrosol offers effective protection against LDL oxidation in vivo and in vitro, but that ex vivo experiments lead to a false-negative result. This false-negative result is achieved by the removal of hydroxytyrosol from LDL during the isolation of the LDL and the subsequent oxidation thereof. Furthermore, hydroxytyrosol has also been shown to reduce cyclo-oxygenase and also reduces platelet aggregation $^{(44,53)}$. Both these effects are associated with a decreased inflammatory response.

It is generally accepted that olive oil decreases oxidative stress $^{(3,32,54,55)}$. Quiles et al. ${ }^{(32)}$ compared olive oil with SFO and its ability to reduce the amount of DNA doublestrand breakage. In this study rats were fed for 6 and 24 months, respectively, with diets containing either olive oil or SFO as a fat source. Some rats continued on this diet after 24 months, in order to determine the mean survival rate on each diet. The beneficial effects of MUFA in olive oil are clear, as it contributes to an increased lifespan of rats and a decrease in reactive oxygen species (ROS)-associated DNA damage. Furthermore, higher concentrations of plasma retinol and coenzyme $\mathrm{Q}_{10}$ were found to be present in the olive oil-treated group when compared with a SFO group. This suggests that there was less oxidative stress in rats supplemented with olive oil than in those supplemented with SFO. Fabiani et al. ${ }^{(56)}$ showed that an extract consisting of a mixture of olive oil antioxidants was able to protect peripheral blood mononuclear cells and promyelocytic leukaemia cells from $\mathrm{H}_{2} \mathrm{O}_{2}$-induced DNA damage. Cell cultures were incubated with various concentrations of antioxidants and $40 \mu \mathrm{M}-\mathrm{H}_{2} \mathrm{O}_{2}$ for $30 \mathrm{~min}$. Antioxidant doses as low as $1 \mu \mathrm{mol} / \mathrm{l}$ were still able to offer significant protection against DNA damage, as measured by the Comet assay.

A study by Briante et al. ${ }^{(50)}$ showed that olive leaf extracts added to olive oil increased the efficacy of the oil's antioxidant effect. This study showed that oleuropein (derived from olive leaf extract) and hydroxytyrosol worked synergistically to prevent LDL oxidation and thus atherosclerosis. This corresponds with the comment by Stahl et al. ${ }^{(24)}$. The addition of these polyphenols to SFO improved the immune status when supplemented to the diet of volunteers for 8 weeks ${ }^{(57,58)}$. Baeza et al. ${ }^{(57)}$ showed that leucocytes had increased glutathione peroxidase activity after 8 weeks of supplementation, while in the study by Díaz et al. ${ }^{(58)}$ no significant changes were seen after 3 weeks of 
enriched oil supplementation. The authors suggested that further studies should be done to determine an optimal supplementation time.

Effects of olive oil on serum lipids. Studies done by Demonty et al. ${ }^{(59)}$ report on hypercholesterolaemic subjects whose diets were supplemented with fish oil, olive oil or enriched oils for 4 weeks. Olive oil supplementation was found to significantly lower LDL concentrations when compared with fish oil supplementation and also led to higher levels of serum TAG than fish oil supplementation, whereas fish oil enriched with plant sterols led to the lowest total cholesterol, LDL and TAG levels. Although olive oil showed a hypocholesterolaemic effect on the serum lipid profile, there is some evidence to suggest that it does not significantly affect the phospholipid profile of the heart or erythrocyte $^{(60)}$. These authors compared the changes in atrium and erythrocyte fatty acid composition of volunteers after different periods of olive oil, flaxseed oil and fish oil supplementation. The olive oil group showed no significant difference from the control group in either the erythrocyte or atrium fatty acid composition. Heyden ${ }^{(46)}$ concluded that MUFA do not play a significant role in reducing cholesterol or LDL-cholesterol. However, squalene present in olive oil has been shown to down-regulate HMG-CoA reductase activity and therefore reduce cholesterol synthesis ${ }^{(31,45)}$

Effects of olive oil on blood pressure. Some studies have shown that olive oil has a beneficial effect on blood pressure. Giliani et al. ${ }^{(30)}$ found that intravenous administration of olive oil extracts reduced both systolic and diastolic blood pressure in normotensive rats. Ferrara et al. ${ }^{(61)}$ showed that patients on an olive oil-supplemented diet were able to reduce their antihypertensive medication, in contrast to patients on a SFO-supplemented diet. Giliani et al. ${ }^{(30)}$ suggested that olive oil may be a $\mathrm{Ca}$ channel agonist and thereby reduce systolic and diastolic blood pressure. Others have suggested that olive oil improve endothelial function by inhibiting the formation of ROS, leading to a NO-mediated vasorelaxation $^{(41,62,63)}$. Other authors have suggested decreased vascular tone and changes in the fatty acid composition of the aorta as a possible mechanism ${ }^{(61)}$.

\section{Olive oil in the ischaemia-reperfusion model}

To our knowledge, little is known about the effects of dietary olive oil supplementation on cardiac ischaemia and reperfusion. Manna et al. ${ }^{(64)}$ performed a study to investigate the effectiveness of oleuropein in offering protection against oxidative stress associated with global myocardial ischaemia and reperfusion. Rat hearts were isolated and perfused with a Langendorff perfusion apparatus. Control hearts were stabilised for $20 \mathrm{~min}$, after which they were subjected to $30 \mathrm{~min}$ of normothermic global ischaemia and $60 \mathrm{~min}$ of reperfusion. Experimental hearts were perfused with oleuropein at a concentration of $50 \mu \mathrm{mol} / \mathrm{l}$ for $15 \mathrm{~min}$ before the induction of ischaemia. Perfusion with oleuropein was able to significantly reduce creatinine kinase release during reperfusion, suggesting that it offered protection against tissue damage. Decreased glutathione and reduced glutathione released in coronary effluent, along with the decreased thiobarbituric acid-reactive substances in heart tissue, indicate that oxidative stress was significantly decreased by oleuropein. Further studies need to be done to confirm cardioprotection by dietary olive oil supplementation and on cardiac health in general.

\section{Benefits of olive oil supplementation}

Even though olive oil contains micronutrients such as polyphenols and squalene, the MUFA in the oil have been thought to be the major active component. MUFA are known to have a beneficial effect on the serum lipid profile and thus decrease the risk of $\operatorname{CVD}^{(13,46,59,60)}$. Furthermore, these fatty acids are stable in oxidative stress conditions and are less likely to react with ROS when compared with PUFA $^{(3,28)}$. MUFA may thus be seen as beneficial to cardiovascular health, as they does not cause negative serum lipid profiles, which are normally associated with SFA. Furthermore, MUFA do not increase oxidative stress by the formation of lipid hydroperoxides, as is the case with PUFA $^{(3,32,35-37,54,55)}$.

Olive oil polyphenols have an antioxidative effect that inhibits LDL oxidation and thus reduces atherosclero$\operatorname{sis}^{(28,41,64)}$. Squalene also exerts an antioxidant effect and inhibits cholesterol synthesis ${ }^{(31,45)}$. Together these micronutrients may affect atherosclerosis by the inhibition of LDL oxidation and reduction of total cholesterol ${ }^{(28,44,56,64,65)}$. Hydroxytyrosol also reduces inflammation by the reduction of pro-inflammatory cyclo-oxygenase and platelet aggregation ${ }^{(44,53)}$.

A number of studies have shown that olive oil supplementation decreases hypertension in human subjects through mechanisms not yet resolved ${ }^{(30,48,61,64,65)}$. Reduction of hypertension has been shown in human studies and animal models with varying supplementation times, or modes of application. In many studies this was not the main aim of the study but rather an additional observation noted.

It is evident that olive oil, due to its micronutrient content and fatty acid composition, can play a vital role in maintaining beneficial serum lipid profiles. Together with its ability to reduce systemic oxidative stress, blood pressure and inflammation, it becomes an appropriate dietary supplement for lowering the risk of CHD.

\section{Sunflower-seed oil}

\section{Refining of sunflower-seed oil}

SFO is produced by refining the seeds of the sunflower. The refinery process includes the following steps: (1) pressing to yield crude oil; (2) acidification and neutralisation; (3) pre-gumming by centrifugation; (4) washing; 5) bleaching; (6) gumming by filtration; and (7) deodorisation ${ }^{(66)}$.

\section{Components of sunflower-seed oil}

This refinery process yields a yellow oil, rich in PUFA, of which the major PUFA is linoleic acid $(60-70 \%)$. Oleic acid and stearic acid are the major MUFA and SFA, respectively. The levels of MUFA and SFA present in SFO 
may vary, depending on the desired product being manufactured $^{(37,51,67-69)}$. Commercially there are three main forms of SFO available. The first is a high-PUFA SFO which consists of up to $75 \%$ PUFA. The second form is a high-MUFA SFO which contains up to $45 \%$ MUFA, whilst the third is a high-stearic acid SFO which may contain up to $14 \%$ stearic acid. These three forms of SFO have very different effects on the serum lipid profile. The most commonly used form of SFO is the high-PUFA SFO. Whilst the high-stearic acid SFO is mainly used in industrial processes, high-MUFA SFO is used for general cooking. SFO contains some natural vitamin $\mathrm{E}$ in the form of tocopherol $^{(37,51,69)}$. Most of the natural tocopherol in SFO is destroyed by refining. It is therefore often artificially supplemented with tocopherol.

$n$-6 PUFA provided by SFO in the diet may play a vital role in the regulation of inflammation, as it is used to produce pro-inflammatory prostaglandins ${ }^{(67,70,71)}$.

\section{Cardiovascular studies with sunflower-seed oil}

Only a few studies have been done with SFO to determine its influence on cardiovascular health. SFO has been used as a control in many studies when compared with other oils ${ }^{(32,51,68,72,73)}$. The choice of SFO as a control may be due to the fact that SFO has shown few effects on the cardiovascular system apart from its beneficial effect on the serum lipid profile ${ }^{(32,51,68,72,73)}$. SFO had little effect on myocardial arrhythmia after 44 weeks of $12 \%$ supplementation in the diet of rats ${ }^{(72)}$. SFO supplementation $(19 \%$ of total diet) could also not induce an anti-thrombotic effect after being supplemented for $22 \mathrm{~d}$ to volunteers ${ }^{(68)}$. Aguilera et al. ${ }^{(51)}$ found little protection against oxidative stress after 4 months of supplementation with SFO. This was supported by similar findings made by Quiles et al. ${ }^{(32)}$ after 6 and 24 months of SFO supplementation (as the sole fat supply) in the diet of rats. Little effect was seen on acute-phase inflammatory markers and apolipoprotein levels after 12 weeks of $3.5 \mathrm{~g}$ SFO supplementation ${ }^{(73)}$.

Effects of sunflower-seed oil on serum lipids. It has been shown that SFO can modulate the serum lipid profile ${ }^{(74-76)}$ and the major finding was shown to be a decrease in total cholesterol and LDL-cholesterol. Lambert et al. ${ }^{(76)}$ supplemented the diets of regularly exercising individuals with $3.90 \mathrm{~g}$ high-MUFA SFO for 12 weeks. A reduction in total cholesterol and LDL-cholesterol of male and female volunteers was found after the supplementation period (men: total cholesterol decreased $6.4 \%$ while LDLcholesterol decreased $11.1 \%$; women: total cholesterol decreased $12.8 \%$ while LDL-cholesterol decreased $8.33 \%$ ). There was also a significant reduction of $12.5 \%$ in HDLcholesterol in women after the 12-week supplementation period. The decreased HDL-cholesterol was ascribed to weight loss or increased dietary consciousness of the participants. Similar findings were made by Nydahl et al. ${ }^{\text {(75) }}$ when they fed a SFO-supplemented diet to 101 volunteers for 3 weeks. During the supplementation period all other oils in the diet were replaced with SFO. A decrease of $4 \%$ in total cholesterol, 5-7\% in LDL-cholesterol and 5\% in apo $\mathrm{B}$ was observed after the 3 weeks. There was virtually no difference in other molecules of the serum lipid profile. Girardet et al. ${ }^{(74)}$ showed a decrease in total serum cholesterol, cholesteryl esters and TAG in rats fed a $12 \%$ SFO-supplemented diet for 1 year. However, in a study done by Aguilera et al. ${ }^{(51)}, 4$ months of dietary supplementation with high-PUFA SFO and virgin olive oil in patients with peripheral vascular disease, SFO supplementation did not affect the serum lipid profile significantly. In this study all meals were cooked in SFO and patients received additional supplements $(15.14 \mathrm{~g}$ of the oil per d). The fat content of the diet in this study may have been excessive, as supplementation with virgin olive oil in this study led to similar results. This pattern was also seen in a study by Quiles et al. ${ }^{(32)}$ where all the fat in the diet was replaced by SFO for 6-24 months.

Sunflower-seed oil as an antioxidant or pro-oxidant. Due to the relative lack of micronutrients in SFO, hydroxytyrosol is added to commercial blends in some instances to increase the antioxidant content. Hydroxytyrosol is a polyphenol which in this case has been shown to improve immunity by increasing leucocyte glutathione peroxidase activity ${ }^{(57,58)}$.

Having large amounts of PUFA in the diet may be worse than large amounts of SFA, even despite its positive impact on the serum lipid profile. A study by Diniz et al. ${ }^{(3)}$ showed that a 5-week diet containing 47.0 g linoleic acid (the major $n-6$ PUFA in most edible oils) per $100 \mathrm{~g}$ fat in the diet leads to higher oxidative stress than a diet containing $81.7 \mathrm{~g}$ saturated fat per $100 \mathrm{~g}$ fat in the diet. In this study, the high PUFA group showed significantly increased tissue hydroperoxide and lipoperoxide concentrations when compared with a high SFA group and the control group. This increase in ROS was accompanied by a significant decrease in superoxide dismutase-, catalase- and citrate synthase activity when compared with a high SFA group and the control group. The high-PUFA diet also contained significantly less glycogen than the other diet groups. Diniz et al. ${ }^{(3)}$ suggest that the increased susceptibility to lipoperoxidation and metabolic shifting is associated with high levels of PUFA in the diet. These negative effects of PUFA supplementation may be so detrimental that they outweigh the positive effects that PUFA have on the serum lipid profile. In another study it was found that SFO supplementation led to statistically significant higher adduct (DNA double-strand breakage) levels in the kidneys, lungs, glandular mucosa, small intestine mucosa and colon mucosa of rats ${ }^{(77)}$. DNA adduct levels were measured after a 4-week diet containing $169 \mathrm{~g}$ SFO, rapeseed oil, coconut oil or olive oil per kg diet. Eder et al. ${ }^{(77)}$ suggested that the increased DNA adduct levels in dietary SFO-supplemented rats may be associated with an increased genotoxic cancer risk. They concluded that the vitamin E content of the SFO evidently did not significantly contribute to a reduction in DNA adduct levels. It would normally be expected that vitamin $\mathrm{E}$ reduces DNA adduct levels, as DNA adducts are the product of lipid peroxidation. However, they speculated that the high linoleic content in SFO had a higher lipid peroxidationinducing effect than the inhibitory effect of the vitamin $\mathrm{E}$ contained in the oil. In another study, these authors also postulated that the vitamin $\mathrm{E}$ content of SFO is not high enough to compensate for the high concentrations of $n-6$ 
PUFA in this oil ${ }^{(37)}$. In this study a similar supplementation was used to that of Eder et al. (77). However, the focus of this study was to determine the effects of the oils on lipid peroxidation in the liver. Aguilera et al. ${ }^{(51)}$ showed that 4 months of dietary SFO supplementation in patients with peripheral vascular disease could not protect LDL from oxidation. The SFO used in this study was enriched with tocopherol $(1200 \mathrm{mg} / \mathrm{kg}$ in total). Despite the increased antioxidants added to the oil, thiobarbituric acid-reactive substances were still found to be significantly higher in the blood of subjects receiving SFO than in those receiving unaltered olive oil. These results argue that the unsaturated fatty acids in SFO lead to high levels of oxidative stress, despite the high levels of antioxidants present in the oil. It can also be concluded that artificial addition of antioxidants to oils may not yield desirable results.

\section{Sunflower-seed oil in the ischaemia-reperfusion model}

To our knowledge, no studies have been done to determine whether SFO supplementation protects against ischaemiareperfusion injury. Judging from studies with SFO in other experimental models, the effects on reperfusion recovery would be minimal ${ }^{(32,51,68,72,73)}$.

\section{Benefits of sunflower-seed oil supplementation}

Despite modulation of the serum lipid profile and the provision of essential fatty acids which may help in the regulation of inflammation, SFO has a neutral effect on the cardiovascular system. This makes SFO an excellent choice as a control oil in cardiovascular research $^{(32,51,68,72,73)}$. The beneficial effect of SFO in ischaemia-reperfusion injury can only be clarified with additional studies.

Due to the positive effects on the serum lipid profile, this oil may lead to a decrease in atherosclerosis and therefore should be considered to be beneficial to cardiovascular health $^{(74-76)}$. In contrast, however, if SFO is not used sparingly in the diet, it may lead to pro-oxidant effects and thus increase susceptibility to cardiovascular disorders.

\section{Fish oil}

\section{Refining of fish oil}

Fish oil is derived from the tissues of oily fish. There is very little refining or chemical alteration that takes place after the recovery of the oil from these fish species ${ }^{(78)}$. Fish oil supplementation in the diet is known to offer protection against various pathological conditions, such as CVD, respiratory diseases, diabetes, depression, cancers, inflammatory and immune renal disorders ${ }^{(70,79,80)}$. After production of fish oil, antioxidants are often added in order to improve storage time. Fish oil also often undergoes microencapsulation before storage in order to improve shelf life and improve the palatability of the product.

\section{Components of fish oil}

Fish is known to be a good source of protein, vitamin $B_{12}$, vitamin $\mathrm{D}$, Se, iodine and long-chain $n-3$ fatty acids. The $n-3$ fatty acids supplied by fish oil are mostly EPA (20: 5) and DHA $(22: 6)^{(60,81,82)}$. In the past many studies focused on the effects of EPA only, as it is provided by fish oil in large amounts. However, recently the focus has shifted to the beneficial effects of DHA on health ${ }^{(82-84)}$. A study by McLennan et al. ${ }^{(85)}$ suggests that DHA may be responsible for most of the beneficial cardiovascular effects of dietary fish oil supplementation. In this study, spontaneously hypertensive rats were fed either DHA or EPA or both in low doses $(0 \cdot 4-1 \%$ of energy intake). DHA proved to be more effective than EPA in reducing ischaemia-induced myocardial arrhythmias, hypertension, thromboxane-like vasoconstrictor responses (in the aorta) and the development of proteinuria after salt loading of the diet in the spontaneously hypertensive rats. The question was subsequently raised whether it is not DHA that may be the principal active component of fish oil in offering cardiovascular protection.

It is of great importance to include sufficient amounts of EPA and DHA in the diet, as the human body can only convert small amounts of $\alpha$-linolenic acid (18: 3) to EPA $(5 \%)$ and DHA (less than $5 \%)^{(86,87)}$. It has been shown that fish oil supplementation is able to significantly increase myocardial levels of DHA and EPA in 1 week of supplementation ${ }^{(60)}$. Volunteers in this study received $10 \mathrm{ml}$ fish oil concentrate per $\mathrm{d}$ for either 7,14 or $21 \mathrm{~d}$. Control groups in this study received either flaxseed oil, olive oil, or no supplementation. Therefore, the increase in DHA and EPA could play a vital role in preventing lifethreatening arrhythmias in supplemented individuals. Furthermore, the increase in DHA and EPA levels in the myocardium was found to be inversely proportional to arachidonic acid levels when fish oil was supplemented in the diet. This indicates that arachidonic acid is replaced by EPA and DHA in cell membranes.

\section{Cardiovascular studies with fish oil}

Effects of fish oil on blood pressure. McLennan et al. ${ }^{(85)}$ showed that dietary supplementation with purified DHA (3.9-10\% of daily energy intake) delayed the onset of hypertension in spontaneously hypertensive rats, while EPA supplementation could not render similar results. They also showed that DHA can inhibit thromboxane-like vasoconstrictor responses in spontaneously hypertensive rat aortas. Furthermore, DHA supplementation delayed the onset of salt loading-induced proteinuria in these spontaneously hypertensive rats with already established hypertension. However, dietary supplementation with EPA did not show similar results in this study. Another study showed that fish oil supplementation was able to decrease diastolic blood pressure by the provision of DHA ${ }^{(84)}$. Purified DHA was tested against a placebo control group in this study and exhibited a decreased diastolic blood pressure. Healthy volunteers were recruited and supplemented with capsules containing $500 \mathrm{mg}$ of either DHA or olive oil for at least 3 months. The antioxidant levels in the two capsules were adjusted to similar levels. Together with a decreased blood pressure, it was also shown that a decrease in heart rate occurred and it was speculated that the decrease in blood 
pressure was caused by the decreased heart rate rather than a decrease in arterial stiffness.

Effects of fish oil on inflammation. In a study on hypercholesterolaemic mice, Chiu et al. ${ }^{(88)}$ showed that fish oil supplementation decreased adhesion molecule expression and some inflammatory markers in early-stage sepsis. Fish oil supplementation was performed in this study over a 3-week period, following a high-fat diet. Late-stage inflammatory markers were not affected and myeloperoxidase activity at the sepsis site was similar in an olive oil-fed group. Chiu et al. ${ }^{(88)}$ concluded that even though fish oil decreases adhesion molecule expression and early-stage inflammatory markers when fed to hypercholesterolaemic mice, it did not cause immunosuppression when sepsis was induced in these animals. As inflammation plays an important role in the pathophysiology of myocardial infarction, reduction in inflammatory markers may prevent the development of heart disease $e^{(18-21)}$.

Effects of fish oil on cardiac arrhythmia. Charnock et al. ${ }^{(72)}$ showed that fish oil mixed in a 1:1 ratio with sheep fat significantly reduced cardiac arrhythmias during coronary occlusion and reperfusion, when compared with rats fed sheep fat only. Diets of rats were supplemented with $12 \%$ of either sheep fat, sheep fat-fish oil blend, physically refined palm oil, chemically refined palm oil or SFO for 12 months. In this study, neither palm oil nor SFO could decrease arrhythmias significantly when compared with the sheep fat-fed control group. In another study it was shown that fish oil was more effective in reducing cardiac arrhythmia during or after ischaemia when compared with olive oil and sheep fat and to a lesser extent $\mathrm{SFO}^{(89)}$. In this study, 30-week-old rats received $12 \%$ olive oil, SFO, fish oil or sheep fat supplementation for 12 weeks. SFO and fish oil supplementation led to significantly lower arrhythmia scores during and after ischaemia when compared with sheep fat. Fish oil, however, led to a much lower incidence of arrhythmia than SFO. These results suggest that PUFA do not only decrease arrhythmia by replacing SFA in the membrane, but that they play an active role in reducing arrhythmia. If it is accepted that PUFA reduce arrhythmia only by the replacement of SFA in the membrane, one would expect that olive oil supplementation would also be able to reduce arrhythmia. However, olive oil was not shown to be able to reduce arrhythmia in this study and therefore the authors suggested another mechanism of protection by PUFA. Furthermore, these results also indicate that $n-3$ PUFA are more effective in reducing arrhythmia than $n$-6 PUFA. It can therefore be accepted that an unknown mechanism of protection can be associated with $n$-3 PUFA but not $n$-6 PUFA. McLennan et al. ${ }^{(85)}$ showed that low doses of purified DHA intake $(0 \cdot 4-1.1 \%$ of daily energy intake) could reduce post-ischaemic cardiac arrhythmias in spontaneously hypertensive rats. Dietary supplementation with a similar dosage of EPA did not have the same effect as DHA. McLennan \& Abeywardena ${ }^{(90)}$ concluded that fish oil is a powerful modulator of arrhythmia. These authors ascribe the ability of fish oil to decrease arrhythmias, especially ventricular fibrillation, to the incorporation of long-chain PUFA (especially DHA) into the myocardium.
They suggest that DHA is the main long-chain PUFA responsible for fish oil cardioprotection, as it is selectively incorporated into myocardial cell membranes. Several possible mechanisms have been suggested for the antiarrhythmic action of long-chain PUFA. These include altered sympathetic innervation to the conduction system and coronary vessels, increased fluidity of the lipid environment of cardiac membranes, different temperature-activity relationships of key membrane enzymes and altered handling of intracellular $\mathrm{Ca}^{2+(91-93)}$. Abdukeyum et al. ${ }^{(94)}$ compared ischaemic preconditioning and several edible oils in their ability to exert anti-arrhythmogenic effects during myocardial ischaemia and reperfusion in an isolated perfused rat heart model. Rats of the fish oil group received $10 \%$ fat (of which $7 \%$ was tuna fish oil) in their diet for 6 weeks. These authors found that the antiarrhythmogenic effects of fish oil supplementation were comparable with that of ischaemic preconditioning. A study by Hlavackova et al. ${ }^{\left({ }^{9}\right)}$ demonstrated significant decreases in ischaemia-reperfusion-induced arrhythmia in rats fed an $n$-3-rich diet when compared with rats fed a SFA- or $n$-6-rich diet. After 10 weeks of supplementation, one group of each diet was exposed to hyperbaric conditions for 5-6 weeks, after which hearts were perfused. Pre-ischaemic hypoxic incidents were shown to increase resistance to ischaemia-reperfusion-induced arrhythmia in the $n$-3-fed group.

Other studies suggest that fish oil or $n-3$ PUFA supplementation does not always offer protection against cardiac arrhythmias. In patients with an implantable cardioverter defibrillator, fish oil supplementation was found to exhibit inconsistent effects. In some cases it was anti-arrhythmic, in others pro-arrhythmic, whilst in some it had no effect ${ }^{(96-100)}$. Burr et al. ${ }^{(96)}$ found that $n-3$ PUFA supplementation led to increased mortality and sudden cardiac death in patients with angina pectoris. Men with chest pain were asked to supplement their diet with two portions of oily fish or $3 \mathrm{~g}$ fish oil per week for 6 months. The control group in this study did not modify their diet. The amount of cardiac and sudden arrhythmic deaths recorded in the fish oil group was significantly higher than that in the control group. The authors could not explain these findings. Den Ruijter et al. ${ }^{(99)}$ demonstrated that $n-3$ PUFA have different electrophysiological effects when they are incorporated into the membranes than when they are in the blood. These authors speculated that this difference in electrophysiological effects may play a role in the seemingly contradictory effects of $n$-3 PUFA supplementation on cardiac arrhythmia. Results of a study by Wilhelm et al. ${ }^{(100)}$ are in agreement with the aforementioned speculation. This study focused on patients with structural heart disease, as most sudden deaths are caused by ventricular arrhythmias in patients with structural heart disease or impaired left ventricular function ${ }^{(101)}$. Wilhelm et al. ${ }^{(100)}$ found that patients with heart failure or structural heart disease showed altered erythrocyte fatty acid profiles. Their results suggest that higher levels of $n-3$ PUFA in erythrocytes may have caused increased cardiac arrhythmia. This in turn suggests that erythrocyte $n-3$ PUFA levels may be seen as an independent risk factor for occurring cardiac arrhythmias. 
Effects of fish oil on serum lipids. In a study by Demonty et al. ${ }^{(59)}$ it was shown that supplementing $7.6 \mathrm{~g}$ fish oil per d for $29 \mathrm{~d}$ was able to decrease serum TAG when compared with olive oil supplementation in hypercholesterolaemic volunteers. This study also demonstrated that plant sterols esterified to fish oil are even more effective in reducing TAG. Plant sterol esters were also able to decrease LDL-cholesterol levels when compared with an olive oil-supplemented control group. Fish oil has beneficial effects on the serum lipid profile. It is known to reduce cholesterol and TAG. Reducing TAG is of great importance to diabetics or metabolic syndrome$\mathrm{X}$ patients, as the increased NEFA associated with these conditions may interfere with cardiac function ${ }^{(102)}$. A study done by D'Allesandro et al. ${ }^{(102)}$ used a sucroserich diet to induce lipotoxicity in rats after 8 months of feeding. Changing the fat source in the diet from maize oil to fish oil for the last 2 months of feeding was able to reduce lipotoxicity. Another study showed that $n-3$ PUFA or fish supplementation may reduce subclinical atherosclerosis ${ }^{(103)}$. These authors used coronary artery $\mathrm{Ca}$ score, common carotid intima-media thickness, internal carotid intima-media thickness and ankle brachial index to measure the level of atherosclerosis in 5488 individuals after evaluating their diets by questionnaire. They concluded that dietary supplementation with $n-3$ PUFA or fish reduced the incidence of subclinical atherosclerosis.

\section{Fish oil in the ischaemia-reperfusion model}

While many studies focused on the effects of fish oil on myocardial arrhythmias caused by ischaemia-reperfusion injury, only a few studies investigated the effects of this oil on functional recovery. Logic would dictate that inhibition of myocardial arrhythmia would ultimately lead to increased functional recovery. However, to our knowledge, no evidence exists to substantiate whether fish oil supplementation may lead to myocardial protection from ischaemia-reperfusion injury.

\section{Benefits of fish oil supplementation}

Dietary fish oil supplementation may play a role in preventing heart disease, heart attacks and atherosclerosis, by reducing serum TAG and LDL-cholesterol $^{(58,88,102)}$. Dietary supplementation of the individual fatty acids, EPA and DHA, showed similar effects to fish oil supplementation. It has been suggested that DHA is the main active component of fish oil and that supplementation of DHA would have similar effects as in fish oil supplementation ${ }^{(90)}$. Evidence also suggests that fish oil can reduce diastolic blood pressure ${ }^{(84,87)}$ and it is known that a reduction in blood pressure is normally associated with better long-term cardiac health ${ }^{(104)}$.

Fish oil may also reduce mortality after a cardiovascular incident, as it plays a role in reducing potentially fatal arrhythmias $^{(72,85,89,90,95)}$. Little is, however, known about the effects of fish oil on infarct size and post-ischaemic functional recovery of the heart.

\section{Palm oil \\ Refining of palm oil}

Palm oil is produced by extraction of the oil from the mesocarp of the fruit of the Ealius genesis plant, commonly known as the oil palm. As for most oils, to be retailed as edible oil it also has to undergo certain refinery processes. Refining of palm oil requires bleaching and deodorisation which may destroy some of the important micronutrients contained in the oil ${ }^{(105)}$.

A novel process has been developed by which palm oil can be refined in order to preserve more micronutrients. Carotenoids and vitamins which would normally be destroyed by the deodorisation and bleaching steps of the refining of palm oil are thus retained ${ }^{(106,107)}$ and these micronutrients, particularly the carotenoids. give red palm oil (RPO) its distinctive red colour.

\section{Components of palm oil}

Palm oil has a balanced fat composition of SFA and unsaturated fatty acids. Of these fats, $51 \%$ are SFA, $39 \%$ MUFA and $10 \%$ PUFA (mostly linoleic acid) ${ }^{(105,108)}$. Palmitic acid is the major SFA in palm oil, making up $44 \%$ of the total fatty acids, with the other $7 \%$ SFA being made up by myristic acid and stearic acid. Most of the MUFA in palm oil are oleic acid. The vitamin E content of palm oil is approximately $62 \mathrm{mg} / \mathrm{g}$, of which $16 \mathrm{mg} / \mathrm{g}$ is made up by $\alpha$-tocopherol, with the balance being made up mostly by tocotrienols $(70 \%)^{(105,107,109)}$. Very little of the carotenoids present in crude palm oil survives the conventional refinery process. The carotene levels in refined, bleached and deodorised palm oil may be as low as $1.2 \mathrm{mg} / \mathrm{g}^{(105)}$.

RPO has a similar fatty acid profile to refined palm oil, with $51 \%$ SFA, $38 \%$ MUFA and $11 \%$ PUFA $^{(106-108)}$. In addition to the fatty acids contained in RPO there is also an abundance of micronutrients naturally occurring in this oil. The colour of the oil is obtained from its high concentrations of carotenoids. RPO contains at least 500 parts per million of carotenoids which include $\alpha-, \beta$ - and $\gamma$-carotene along with some lycopene and xanthophylls. Of these carotenoids, $80-90 \%$ are $\alpha$ - or $\beta$-carotene, which occurs in a ratio of 2:1 in the favour of $\beta$-carotene $(375 \mathrm{mg} / \mathrm{g})^{(110,111)}$. RPO is also unique among oils due to its high vitamin $\mathrm{E}$ content. It contains 560-1000 parts per million of vitamin E, of which approximately $18-22 \%$ is tocopherols and $78-82 \%$ tocotrienols ${ }^{(27,106,107)}$. This makes RPO the oil with the highest content of tocotrienols of all vegetable oils. The most abundant tocotrienol in RPO is $\gamma$-tocotrienol, which is a potent antioxidant that reduces cholesterol production and platelet aggregation ${ }^{(112-116)}$. Serbinova et al. ${ }^{(117)}$ showed that tocotrienols are forty to sixty times more potent as an antioxidant than tocopherol in a study done on palm oil vitamin $\mathrm{E}$ in an isolated perfused rat heart model. RPO also contains squalene, phytosterols and co-enzyme Q10 ${ }^{(106,107,118)}$. RPO has been the focus of many studies aimed at improving the vitamin A status of certain communities ${ }^{(119-121)}$. The main reason for RPO being the focus of these studies is the high carotene content of the oil and the major finding was that RPO is effective in combating vitamin A deficiency by the provision of ample 
carotene in the diet. RPO may thus prevent complications associated with vitamin A deficiency.

\section{Cardiovascular studies with palm oil}

Effects of palm oil on serum lipids. Most of the studies done on palm oil focused on its effect on the serum lipid profile ${ }^{(54,55,115,122-127)}$. Historically the perception of dietitians and clinicians was that palm oil would have a negative effect on the serum lipid profile, due to the relatively high levels of SFA in the oil. However, research has proven this perception to be wrong, and suggested possible mechanisms by which palm oil may in fact reduce serum cholesterol. First, palmitic acid does not have an impact negatively on the serum lipid profile ${ }^{(55,108,128)}$. Second, the TAG conformation in palm oil has SFA on the sn-1 and sn-3 positions of the glycerol backbone, and unsaturated fatty acids on the sn- 2 position in $75-87 \%$ of these molecules. This TAG conformation leads to absorption of more unsaturated fats than saturated fats, as the fatty acid on the sn-2 position is absorbed preferentially to those in the sn- 1 and sn-3 positions ${ }^{(54,127,129)}$. Furthermore, tocotrienols contained within palm oil have been shown to inhibit HMG-CoA reductase, a rate-limiting enzyme in cholesterol biosynthesis ${ }^{(54,115,124,130)}$. RPO has a similar fatty acid composition to refined palm oil, and thus it also has a neutral effect on the serum lipid profile. It also has a similar tocotrienol content to refined palm oil. It may therefore be accepted that RPO has similar effects on the serum lipid profile to palm oil.

In a study done on rabbits, Hornstra ${ }^{(122)}$ found that palm oil was significantly less atherogenic than fish oil, linseed oil and olive oil. These results were obtained after the diet of these rabbits was supplemented with the different oils for 18 months. Wilson et al. ${ }^{(105)}$ investigated the effect of palm oil on cholesterol concentrations and aortic cholesterol accumulation in a hypercholesterolaemic hamster model. They found that supplementation of $10 \%$ palm oil to a standard hamster diet for 10 weeks had reduced total cholesterol, non-HDL-cholesterol and TAG when compared with a coconut-supplemented group. In addition, they demonstrated that palm oil supplementation can be associated with significantly lower lipid hydroperoxide formation than coconut oil supplementation. The authors suggest that this may be due to different antioxidant pathways associated with the oils, or an intrinsic effect of dietary fats. In the same study, RPO also reduced total cholesterol and non-HDL-cholesterol when compared with a coconut oil-supplemented group. In addition, the RPO led to a significant increase in HDL-cholesterol in this study. Results showed that RPO had the highest non-esterified cholesterol:cholesteryl ester ratio, indicating that it was the least atherogenic of all the oil preparations used. Zhang et al. ${ }^{(131)}$ showed that RPO did not change the serum lipid profile of volunteers fed a RPO-supplemented diet (60\% of fat was RPO) for $42 \mathrm{~d}$. They also found that the carotenoid and tocopherol levels of the volunteers were significantly increased after the diet period. Qureshi et al. ${ }^{(115)}$ supplemented fifteen hypercholesterolaemic subjects with $800 \mathrm{mg}$ tocotrienol-rich fraction (TRF; extracted from palm oil) for 4 weeks. There was a $20 \%$ reduction in total cholesterol and a $27 \%$ reduction in LDL-cholesterol in these subjects after the 4 weeks. In another study, the same authors showed that supplementation of a blend of tocotrienols for 4 weeks could reduce the total cholesterol levels of hypercholesterolaemic individuals by $10 \%$. In a study by Salinas et al. ${ }^{(132)}$ it was found that a $35 \mathrm{~d}$ supplementation of a deodorised and bleached form of palm oil could significantly reduce total cholesterol and increase HDL-cholesterol in rats with induced hyperlipidaemia by the addition of $5 \%$ egg yolk powder to the diet. It was concluded that the high concentrations of micronutrients and MUFA in palm oil altered the serum lipid profile favourably in hyperlipidaemic rats. In a study by Girardet et al. ${ }^{(74)}$, rats were fed a diet containing $12 \%$ palm oil for 1 year and found that palm oil caused increased total serum cholesterol, but that it was accompanied with a lower aortic accumulation of cholesteryl esters when compared with SFO, rapeseed oil, soyabean oil and butter. In the light of previous studies the palm oil-associated increase in cholesterol in this study may be due to the longer feeding period.

Effects of palm oil on cardiac arrhythmia. Research has shown that palm oil may have some anti-arrhythmogenic properties. Charnock et al. ${ }^{(72)}$ demonstrated that palm oil had some efficacy in reducing arrhythmia during reperfusion. These authors supplemented rats with $12 \%$ fat in the diet for 1 year, before inducing ischaemia and reperfusion in vivo. They also noted that the incidence of ventricular fibrillation decreased in the palm oil group when compared with a control group which was supplemented with sheep fat. Abeywardena \& Charnock ${ }^{(133)}$ found that that the antiarrhythmogenic effect of palm oil was significantly lower than that of SFO. In this study, rat diets were supplemented for 9 months with $12 \%$ of the oils before induction of ischaemia-reperfusion.

\section{Palm oil in the ischaemia-reperfusion model}

The tocotrienols present in palm oil have been shown to offer protection from myocardial ischaemia-reperfusion injury in the isolated perfused rat heart model ${ }^{(70,117)}$. In both studies, vitamin E components of palm oil were fractionated from the oil. Serbinova et al. ${ }^{(117)}$ perfused isolated rat hearts with TRF. They found that TRF could increase postischaemic functional recovery and suggested that the antioxidant activity of the TRF was responsible for the protection. In the study by Das et al. ${ }^{(71)}$, individual isoforms of tocotrienols ( $\alpha, \beta$ and $\delta$ ) were fed to rats by oral administration. Three concentrations of tocotrienols $(0.35$, 1 or $3.5 \%$ ) were fed to the rats for 2 or 4 weeks. Das et al. ${ }^{71)}$ demonstrated a decreased infarct size with tocotrienol supplementation when compared with a control group. Similar decreases in infarct size could be achieved with $\alpha$ tocotrienol and $\gamma$-tocotrienol supplementation. The authors proposed that the antioxidant activity of tocotrienols may play a role in the protection offered against ischaemiareperfusion injury, but emphasised the ability of tocotrienols to alter protein kinase signalling. In this study, decreased infarct size was accompanied by increased phosphorylation of protein kinase $\mathrm{B}(\mathrm{PKB}) / \mathrm{Akt}$. 
Palm oil supplementation may also reduce oxidative stress associated with ischaemia-reperfusion injury. Narang et al. ${ }^{(134)}$ supplemented 5 or $10 \%$ palm oil to the diet of rats for $30 \mathrm{~d}$. They found an increase in glutathione peroxidase, catalase and superoxide dismutase activities in the hearts of rats supplemented with palm oil. This was associated with lower thiobarbituric acid-reactive substance measurements. The authors concluded that palm oil augments the activities of endogenous antioxidant enzymes, and thus reduces oxidative stress.

To our knowledge, only a few studies have been conducted on dietary RPO supplementation related to cardiovascular health. Most studies on RPO dealt with vitamin A deficiencies. However, in recent studies the effect of RPO in the ischaemic-reperfusion model was investigated. The group of Van Rooyen et al. have published several papers on the protective effect of RPO against ischaemia-reperfusion injury ${ }^{(135-142)}$.

Esterhuyse et al. ${ }^{(135)}$ demonstrated that dietary RPO supplementation could offer protection against ischaemiareperfusion injury in the isolated perfused heart. These authors fed rats $200 \mu \mathrm{l}$ RPO per d for 5-6 weeks before perfusions were performed. Recent studies published on RPO have mostly used the ischaemic-reperfused isolated rat heart model ${ }^{(136,137)}$. A follow-up study showed that dietary RPO supplementation could offer similar protection in cholesterol-fed rats where rats were placed on a diet that included $2 \%$ synthetic cholesterol with or without $200 \mu \mathrm{l}$ $\mathrm{RPO}^{(136)}$. The cholesterol-supplemented group showed decreased functional recovery when compared with standard rat chow-fed controls. RPO supplementation could, however, significantly increase functional recovery in the hearts of cholesterol-supplemented animals. Esterhuyse et al. (136) suggested that protection was offered in cholesterol-fed rats via a different pathway when compared with rats fed a standard rat chow diet based on the finding that the NO-cyclic GMP signalling pathway was not affected by RPO supplementation in cholesterol-fed rats.

Bester et al. (137) showed that dietary RPO supplementation could offer protection against ischaemia-reperfusion injury, irrespective of the fat content of the diet. In this study the diets were designed to be isoenergetic to investigate whether increased energy in the RPO group may have played a role in previous studies. One diet contained high levels of SFA, while the other contained high levels of PUFA. RPO supplementation was able to offer protection against ischaemia-reperfusion injury in both diets when compared with controls. These authors suggested several mechanisms for RPO-mediated protection against ischaemia-reperfusion injury. Amongst the proposed mechanisms are the NO-cyclic GMP pathway, phosphorylation of mitogen-activated protein kinases and scavenging of deleterious ROS by $\operatorname{RPO}^{(136-140)}$. In the study by Engelbrecht et al. ${ }^{(138)}$, the RPO supplementation caused increased phosphorylation of $\mathrm{PKB} / \mathrm{Akt}$ and $\mathrm{p} 38$, and decreased phosphorylation of c-Jun NH2-terminal kinase (JNK) and extracellular signal-regulated kinase (ERK) in rats fed a standard rat chow diet supplemented with $200 \mu \mathrm{l}$ RPO for 5-6 weeks. These findings were accompanied by decreased caspase activation and poly ADP ribose polymerase (PARP) cleavage, as well as improved aortic output recovery, indicating a protective effect. The mitogen-activated protein kinase activation was markedly different when a similar diet was supplemented with $2 \%$ cholesterol $^{(140)}$. These authors supplemented cholesterol and RPO simultaneously for 5-6 weeks in order to determine whether cholesterol supplementation altered the effects of RPO on mitogen-activated protein kinase signalling. They found increased caspase activation and decreased PARP cleavage with RPO supplementation. This was accompanied by increased ERK phosphorylation together with decreased JNK and p38 phosphorylation in the RPO-supplemented group when compared with the cholesterol-fed controls. This indicates that RPO supplementation activated survival kinase pathways and inhibited apoptotic pathways. These changes led to a significantly greater aortic output recovery in the RPOsupplemented group than in the cholesterol-fed controls. Engelbrecht et al. ${ }^{(142)}$ found in a similar model that dietary RPO supplementation increases PKB/Akt phosphorylation via a phosphatidylinositol 3-kinase (PI3K)-independent pathway. They perfused hearts in the presence of wortmannin, which is a known inhibitor of PI3K. Despite inhibition of PI3K in this study, RPO could still induce increased phosphorylation of $\mathrm{PKB} / \mathrm{Akt}$, and induce increased reperfusion functional recovery.

The above-mentioned studies showed that hearts of dietary RPO-supplemented rats have significantly increased cyclic GMP levels early in ischaemia ${ }^{(135-137,139)}$. Hearts of dietary RPO-supplemented rats showed increased levels of NO within the myocytes. These findings suggest that dietary RPO supplementation leads to an increased NO conservation in the myocytes, and therefore stronger NOcyclic GMP signalling. Both these signalling molecules are antagonists of cAMP and would thus offer protection against ischaemia-reperfusion injury by blocking intracellular Ca overload ${ }^{(143)}$. Khairallah et al. ${ }^{(144)}$ suggested that increased levels of cyclic GMP may prevent intracellular TAG accumulation in cardiomyocytes and that this may offer further protection. Van Rooyen et al. ${ }^{(141)}$ argued that not one, but a few mechanisms may be involved in the protective effect of RPO against ischaemiareperfusion injury. Therefore, it is not conclusive that the pro-survival Akt pathway, the anti-apoptotic pathway or the NO-cyclic GMP pathway alone is responsible for this protection. The complexity of the composition of the oil, including $50 \%$ unsaturated fatty acids and several highly potent antioxidants, may well be the strong point of this oil.

\section{Benefits of palm oil supplementation}

Palm oil may be able to offer protection against ischaemiareperfusion injury, through the TRF contained in it ${ }^{(71,117)}$. Palm oil may also lead to the reduction of oxidative stress, and this could play a role in the reduction of ischaemiareperfusion injury ${ }^{(134)}$.

It has also been suggested that palm oil may have some anti-arrhythmogenic effects, which may reduce sudden death after ischaemic incidents ${ }^{(72)}$.

Palm oil may also exert a neutral or positive effect on the serum lipid profile through the effects of its fatty acid composition and tocotrienols ${ }^{(54,55,115,122-127)}$. 
Few studies have been performed using RPO that focused on the baseline effects of this oil on cardiovascular health. RPO supplementation does, however, offer protection against myocardial ischaemia-reperfusion injury via several suggested mechanisms ${ }^{(136-141)}$. The mechanisms suggested for the aforementioned protection include upregulation of the NO-cyclic GMP signalling pathway and increased phosphorylation of $\mathrm{PKB} / \mathrm{Akt}$.

This oil has positive effects on the serum lipid profile and reduces oxidative stress ${ }^{(71,105,131,132)}$. Furthermore, as refined palm oil and RPO have comparable contents except for the higher micronutrient (mainly carotenoids) content of RPO, RPO may exhibit similar anti-arrhythmogenic effects, as is suggested of palm oil ${ }^{(72)}$.

RPO has been shown to be effective in reducing vitamin A deficiency and associated ocular disorders. This is due to the pro-vitamin A provided by $\mathrm{RPO}^{(119-121)}$.

The refinery process of RPO, which retains more of the micronutrients, makes it unnecessary to add more antioxidants to the oil. Addition of antioxidants to palm oil does not offer similar protection as natural $\mathrm{RPO}^{(105)}$.

RPO contains high concentrations of tocotrienols and carotenoids and research has shown that different carotenes may not only work synergistically with each other, but also with tocotrienols to achieve greater antioxidant effects ${ }^{(26,27)}$.

\section{Discussion and conclusion}

More research needs to be done on edible oil products. Many studies focus on only certain components of the oils that are normally employed during research. There also seems to be a trend that each oil is only used in studies to obtain specific types of endpoints which have previously been associated with that oil. These approaches frustrate any attempt to speculate what the effects of dietary supplementation of edible oils on cardiovascular health would be. In our opinion, the best way to determine the effects of dietary edible oil supplementation on the cardiovascular system would be to supplement the whole oil (unmodified) to the diet of research subjects and subsequently measuring a broad spectrum of endpoints, irrespective of the oil used.

From the studies that have been done, however, it is clear that the oils that have been reviewed in the present article all may form part of a healthy diet. Each oil seems to have some beneficial effects. It may be that some undesirable effects are still to be elucidated in these oils and there is still controversy about the beneficial effects of some of these oils. However, from the current literature, these oils all have more beneficial effects on cardiovascular health than detrimental effects, if supplemented to the diet in acceptable proportions.

Most studies performed with olive oil focused on the anti-oxidative effects of the polyphenols in this oil and many researchers used only extracts of the antioxidants in the olive oil to perform their studies. The inhibition of oxidative stress along with the reduction of serum cholesterol, which is associated with olive oil, would lead to a reduced risk of IHD. However, it is difficult to predict if this oil would have any protective effects against ischaemia-reperfusion injury. It is also unclear if this oil would have anti-arrhythmogenic effects. More research needs to be done using this oil as a dietary supplement, with the focus of elucidating its effects on ischaemia-reperfusion injury. This oil may, however, be advised for use to individuals with dyslipidaemia, high blood pressure or a family history of heart disease.

SFO has mostly been used as a control to compare other oils with. The only clear effects of this oil on cardiovascular health are reduction of serum cholesterol, and some mild anti-arrhythmogenic effects. This oil has also been shown to have a pro-oxidant effect if used for frying. Use of SFO is therefore less desirable than the other oils mentioned in the present review.

Dietary fish oil supplementation inhibits arrhythmia in healthy individuals. This finding could not be repeated with regularity in individuals with a history of heart disease. More research needs to be done in order to elucidate the reasons for the variations in this effect by fish oil. Little is known of other effects that fish oil may have on the cardiovascular system. The effects of dietary fish oil supplementation on the risk factors for IHD, and its effects on ischaemia-reperfusion injury, should be investigated. Fish oil is, however, the only oil that can with any certainty be recommended to individuals who are at risk of cardiac arrhythmia.

Palm oil has mostly been used in studies to determine its effects on the serum lipid profile. This oil has a neutral effect on the serum lipid profile and may even reduce atherosclerosis and prevent IHD. The few studies done with palm oil on arrhythmogenesis are non-conclusive. However, palm oil may have some minor anti-arrhythmogenic effects. Furthermore, the studies performed with TRF extracts from palm oil suggest that palm oil may offer protection against ischaemia-reperfusion injury. These effects, however, should be subjected to further study in a dietary supplementation model.

An advantage of doing research on the effects of RPO is that it contains the same components as refined palm oil, except for the presence of more micronutrients. We can therefore assume investigations performed using palm oil would also apply to RPO. Studies performed with RPO confirm this assumption, and additionally the presence of more micronutrients often led to enhanced effects due to their synergistic action. RPO was shown to have a neutral or slightly lowering effect on the serum lipid profile. Furthermore, our research has shown that RPO offers protection against ischaemia-reperfusion injury when supplemented to the diet. More research should be done with RPO to confirm its effects on risk factors for IHD and cardiac arrhythmia.

As palm oil has only mild effects on the serum lipid profile it is not known whether individuals who are at risk of CVD will benefit from its consumption. However, it is highly advised that these individuals do consume this oil, as it is one of the few oils that have been shown to effectively protect against myocardial ischaemia-reperfusion injury.

\section{Acknowledgements}

The present review received no specific grant from any funding agency in the public, commercial or not-for-profit sectors. 
D. B. and J. V. R. contributed mostly to the design and writing of the manuscript, while A. J. E. and E. J. T. were involved in reviewing the manuscript.

The authors confirm that there are no conflicts of interest.

\section{References}

1. Elson CE \& Quereshi AA (1995) Coupling the cholesteroland tumour-suppresisve actions of palm oil to the impact of its minor constituents on 3-hydroxy-3-methylglutaryl coenzyme areductase activity. PLEFA 52, 205-208.

2. Schrauwen P \& Westerterp KR (2000) The role of high-fat diets and physical activity in the regulation of body weight. Br J Nutr 84, 417-427.

3. Diniz YSA, Cicogna AC, Padovani CR, et al. (2004) Diets rich in saturated and polyunsaturated fatty acids: metabolic shifting and cardiac health. Nutrition 20, 230-234.

4. Puskas LG, Nagy ZB, Girics Z, et al. (2004) Cholesterol diet-induced hyperlipidaemia influences gene expression pattern of rat hearts: a DNA micoarray study. FEBS Lett 562, 99-104.

5. Horribon DF (1990) $\gamma$ Linoleic acid: an intermediate in fatty acid metabolism with potential as an ethical pharmaceutical and as a food. Rev Contemp Pharmacother 1, 1-45.

6. Das UN (1990) $\gamma$-Linolenic acid, arachidonic acid and eicosapentaenoic acid as potential anti-cancer drugs. Nutrition 6, 429-434.

7. Das UN (2004) Long-chain polyunsaturated fatty acids interact with nitric oxide, superoxide anion, and transforming growth factor- $\beta$ to prevent human essential hypertension. Eur J Clin Nutr 58, 195-203.

8. Das UN (2005) Essential fatty acids: biochemistry, physiology, and pathology. Biotech J 1, 420-439.

9. Suresh Y \& Das UN (2006) Differential effect of saturated, monounsaturated, and polyunsaturated fatty acids on alloxan induced diabetes mellitus. PLEFA 74, 199-213.

10. Das UN (2007) A defect in the activity of $\Delta 6$ and $\Delta 5$ desaturases may be a factor in the initiation and progression of atherosclerosis. PLEFA 76, 251-268.

11. Banegas JR, Rodriguez-Artalejo F, Graciani A, et al. (2003) Mortality attributable to cardiovascular risk factors in Spain. Eur J Clin Nutr 57, Suppl., S18-S21.

12. Jemal A, Ward E, Hao Y, et al. (2005) Trends in the leading causes of death in the United States, 1970-2002. JAMA 294, 1255-1259.

13. Expert Panel on Detection, Evaluation, and Treatment of High Blood Cholesterol in Adults (2001) Executive Summary of the Third Report of the National Cholesterol Education Program (NCEP) Expert Panel on Detection, Evaluation, and Treatment of High Blood Cholesterol in Adults (Adult Treatment Panel III). JAMA 285, 2486-2497.

14. Assman G, Schulte H \& von Eckardstein A (1996) Hypertriglyceridemia and elevated lipoprotein(a) are risk factors for major coronary events in middle-aged men. Am J Cardiol 77, 1179-1184.

15. Jeppensen J, Hein HO, Suadicani P, et al. (1998) Triglyceride concentration and ischemic heart disease: an eight-year follow-up in the Copenhagen Male Study. Circulation 97, 1029-1036.

16. Austin MA, Hokanson JE \& Edwards KL (1998) Hypertriglyceridemia as a cardiovascular risk factor. Am J Cardiol 81, 7B-12B.

17. Cullen $\mathrm{P}$ (2000) Evidence that triglycerides are an independent coronary heart disease risk factor. Am J Cardiol 86, 943-949.
18. Mullane KM, Read N, Salmon JA, et al. (1984) Role of leukocytes in acute myocardial infarction in anesthetized dogs: relationship to myocardial salvage by anti-inflammatory drugs. J Pharmacol Exp Ther 228, 510-522.

19. Braunwald E \& Kloner RA (1985) Myocardial reperfusion: a double-edged sword? J Clin Invest 76, 1713-1719.

20. Jones SP \& Lefer DJ (2000) Myocardial reperfusion injury: insights gained from gene-targeted mice. News Physiol Sci 15, 303-308.

21. Carnieto A, Dourado PMM, Da Luz PL, et al. (2009) Selective cyclooxygenase-2 inhibition protects against myocardial damage in experimental acute ischemia. Clinics 64, 245-252.

22. Palozza P \& Krinsky NI (1992) $\beta$-Carotene and $\alpha$ tocopherol are synergistic antioxidants. Arch Biochem Biophys 297, 184-187.

23. Böhm F, Edge R, McGarvey DJ, et al. (1998) $\beta$-Carotene with vitamins $\mathrm{E}$ and $\mathrm{C}$ offers synergistic cell protection against NOx. FEBS Lett 436, 387-389.

24. Stahl W, Junghans A, De Boer B, et al. (1998) Carotenoid mixtures protect multilamellar liposomes against oxidative damage: synergistic effects of lycopene and lutein. FEBS Lett 427, 305-308.

25. Age-Related Eye Disease Study Research Group (2001) A randomized, placebo-controlled, clinical trial of high-dose supplementation with vitamins $\mathrm{C}$ and $\mathrm{E}, \beta$ carotene, and zinc for age-related macular degeneration and vision loss. AREDS report no. 8. Arch Ophthalmol 119, 1417-1436.

26. Stahl W \& Sies H (2005) Bioactivity and protective effects of natural carotenoids. Biochim Biophys Acta 1740, $101-107$.

27. Schroeder MT, Becker EM \& Skibsted LH (2006) Molecular mechanism of antioxidant synergism of tocotrienols and carotenoids in palm oil. J Agric Food Chem 54, 3445-3453.

28. Owen RW, Mier W, Giacosa A, et al. (2000) Phenolic compounds and squalene in olive oils: the concentration and antioxidant potential of total phenols, simple phenols, secoiridoids, lignans and squalene. Food Chem Toxicol 38, 647-659.

29. Brenes M, Romero CN, Garciäa A, et al. (2004) Phenolic compounds in olive oils intended for refining: formation of 4-ethylphenol during olive paste storage. J Agric Food Chem 52, 8177-8181.

30. Giliani AH, Khan AU, Shah AJ, et al. (2005) Blood pressure lowering effect of olive is mediated through calcium channel blockade. Int J Food Sci Nutr 56, 613-620.

31. Newmark HL (1997) Squalene, olive oil, and cancer risk: a review and hypothesis. Cancer Epidemiol Biomarkers Prev 6, 1101-1103.

32. Quiles JL, Ochoa JJ, Ramirez-Tortosa C, et al. (2004) Dietary fat type (virgin olive vs. sunflower oils) affects agerelated changes in DNA double-strand-breaks, antioxidant capacity and blood lipids in rats. Exp Gerontol 39, 1189-1198.

33. O'Farrell S \& Jackson MJ (1997) Dietary polyunsaturated fatty acids, vitamin $\mathrm{E}$ and hypoxia/reoxygenation-induced damage to cardiac tissue. Clin Chim Acta 267, 197-211.

34. Turpeinen AM, Basu S \& Mutanen M (1998) A high linoleic acid diet increases oxidative stress in vivo and affects nitric oxide metabolism in humans. PLEFA 59, 229-233.

35. Newaz MA, Yousefipour Z, Nawal N, et al. (2003) Nitric oxide synthase activity in blood vessels of spontaneously hypersensitive rats: antioxidant protection by $\gamma$-tocotrienol. J Physiol Pharmacol 54, 319-327. 
36. Wahle KW, Caruso D, Ochoa JJ, et al. (2004) Olive oil and modulation of cell signaling in disease prevention. Lipids 39, 1223-1231.

37. Eder E, Wacker M, Lutz U, et al. (2006) Oxidative stress related DNA adducts in the liver of female rats fed with sunflower-, rapeseed-, olive- or coconut oil supplemented diets. Chem Biol Interact 159, 81-89.

38. Lercker G \& Rodríguez-Estrada MT (2000) Chromatographic analysis of unsaponifiable compounds of olive oils and fat-containing foods. J Chromatogr A 881, 105-129.

39. Caravaca AMG, Pancorbo AC, Diaz BC, et al. (2005) Electrophoretic identification and quantitation of compounds in the polyphenolic fraction of extra-virgin olive oil. Electrophoresis 26, 3538-3551.

40. Tuck KL \& Hayball PJ (2002) Major phenolic compounds in olive oil: metabolism and health effects. J Nutr Biochem 13, 636-644.

41. Perona JS, Cabello-Moruno R \& Ruiz-Gutierrez V (2006) The role of virgin olive oil components in the modulation of endothelial function. $J$ Nutr Biochem 17, 429-445.

42. Romero C, Medina E, Vargas J, et al. (2007) In vitro activity of olive oil polyphenols against Helicobacter pylori. J Agric Food Chem 55, 680-686.

43. Montedoro G, Servilli M, Baldioli M, et al. (1993) Simple and hydro-lysable phenolic compounds in virgin olive oil 3. Spectroscopic characterisation of the secoiridoid derivatives. J Agric Food Chem 41, 2228-2234.

44. Visioli F, Poli A \& Gall C (2002) Antioxidant and other biological activities of phenols from olives and olive oil. Med Res Rev 22, 65-75.

45. Relas H, Gylling H \& Miettinen TA (2000) Dietary squalene increases cholesterol synthesis measured with serum noncholesterol sterols after a single oral dose in humans. Atherosclerosis 152, 377-383.

46. Heyden S (1994) Polyunsaturated and monounsaturated fatty acids in the diet to prevent coronary heart disease via cholesterol reduction. Ann Nutr Metab 38, 117-122.

47. Carrasco-Pancorbo L, Cerretani A, Bendini A, et al. (2005) Evaluation of the antioxidant capacity of individual phenolic compounds in virgin olive oil. J Agric Food Chem 53, 8918-8925.

48. Keys A, Menotti A, Karvonen MJ, et al. (1986) The diet and 15-year death rate in the Seven Countries Study. Am J Epidemiol 124, 903-915.

49. Vissers MN, Zock PL, Wiseman SA, et al. (2001) Effect of phenol-rich extra virgin olive oil on markers of oxidation in healthy volunteers. Eur J Clin Nutr 55, 334-341.

50. Briante R, Febbraio F \& Nucci R (2004) Antioxidant/ prooxidant effects of dietary non-flavonoid phenols on the $\mathrm{Cu}^{2+}$-induced oxidation of human low-density lipoprotein (LDL). Chem Biodivers 1, 1716-1729.

51. Aguilera CM, Mesa MD, Ramirez-Tortosa MC, et al. (2004) Sunflower oil does not protect against LDL oxidation as virgin olive oil does in patients with peripheral vascular disease. Clin Nutr 23, 673-681.

52. Rietjens SJ, Bast A \& Haenen GRMM (2007) New insights into controversies on the antioxidant potential of the olive oil antioxidant hydroxytyrosol. J Agric Food Chem 55, 7609-7614.

53. Fabiani R, De Bartolomeo A, Rosignoli P, et al. (2002) Cancer chemoprevention by hydroxytyrosol isolated from virgin olive oil through G1 cell cycle arrest and apoptosis. Eur J Cancer Prev 11, 351-358.

54. Theriault A, Chao J, Wang QI, et al. (1999) Tocotrienol: a review of its therapeutic potential. Clin Biochem 32, $309-319$.
55. Kritchevsky D (2000) Impact of red palm oil on human nutrition and health. Food Nutr Bull 21, 182-188.

56. Fabiani R, Rosignoli P, De Bartolomeo A, et al. (2008) Oxidative DNA damage is prevented by extracts of olive oil, hydroxytyrosol, and other olive phenolic compounds in human blood mononuclear cells and HL60 cells. Am J Nutr 138, $1411-1416$.

57. Baeza I, De Castro NM, Díaz LE, et al. (2008) Effect of oil (sunflower oil) consumption with added hydroxytyrosol (natural antioxidant) on antioxidant variables in leucocytes from healthy adults. Proc Nutr Soc 67, OCE, E26.

58. Díaz LE, Gómez S, Nova E, et al. (2008) Immunomodulation and antioxidant capacity of hydroxytyrosol present at oleic acid-rich sunflower oil. Proc Nutr Soc 67, OCE, E2.

59. Demonty I, Chan YM, Pelled D, et al. (2006) Fish-oil esters of plant sterols improve the lipid profile of dyslipidemic subjects more than do fish-oil or sunflower oil esters of plant sterols. Am J Clin Nutr 84, 1534-1542.

60. Metcalf RG, James MJ, Gibson RA, et al. (2007) Effects of fish-oil supplementation on myocardial fatty acids in humans. Am J Clin Nutr 85, 1222-1228.

61. Ferrara LA, Raimondi AS, d'Episcopo L, et al. (2000) Olive oil and reduced need for antihypertensive medications. Arch Intern Med 160, 837-842.

62. Ruiz-Gutierrez V, Muriana FJ, Guerrero A, et al. (1997) Role of dietary oleic acid from different sources on fatty acid composition of erythrocyte membrane and blood pressure in healthy subjects. J Nutr Biochem 8, 689-695.

63. Alonso A, Ruiz-Gutierrez V \& Martinez-Gonzalez MA (2006) Monounsaturated fatty acids, olive oil and blood pressure: epidemiological, clinical and experimental evidence. Public Health Nutr 9, 251-257.

64. Manna C, Migliardi V, Golino P, et al. (2004) Oleuropein prevents oxidative myocardial injury induced by ischaemia and reperfusion. J Nutr Biochem 15, 461-466.

65. Patrick L \& Uzick M (2001) Cardiovascular disease: $\mathrm{C}$-reactive protein and the inflammatory disease paradigm: HMG-CoA reductase inhibitors, $\alpha$-tocopherol, red yeast rice, and olive oil polyphenols. A review of the literature. Altern Med Rev 6, 248-271.

66. Zitouni N, Errahali Y, Metche M, et al. (2000) Influence of refining steps on trace allergenic protein content in sunflower oil. J Allergy Clin Immunol 106, 962-967.

67. Navarro MD, Hortelano P, Periago JL, et al. (1992) Effect of dietary olive and sunflower oils on the lipid composition of the aorta and platelets and on blood eicosanoids in rats. Arteriosc Thromb 12, 830-835.

68. Larsen LF, Jespersen J \& Marckmann P (1999) Are olive oil diets antithrombotic? Diets enriched with olive, rapeseed, or sunflower oil affect postprandial factor VII differently. Am J Clin Nutr 70, 976-982.

69. AbuGhazaleh AA, Felton DO \& Ibrahim SA (2007) Milk conjugated linoleic acid response to fish oil and sunflower oil supplementation to dairy cows managed under two feeding systems. J Dairy Sci 90, 4763-4769.

70. Simopoulos AP (1991) Omega-3 fatty acids in health and disease and in growth and development. Am J Clin Nutr $\mathbf{5 4}$ 438-463.

71. Das S, Lekli I, Das M, et al. (2008) Cardioprotection with palm oil tocotrienols: comparision of different isomers. Am J Physiol Heart Circ Physiol 294, 970-978.

72. Charnock JS, Sundram K \& Abeywardena MY et al. (1991) Dietary fats and oils in cardiac arrhythmia in rats. Am J Clin Nutr 53, 1047S-1049S.

73. De Roos B, Geelen A, Ross K, et al. (2008) Identification of potential serum biomarkers of inflammation and lipid 
modulation that are altered by fish oil supplementation in healthy volunteers. Proteomics 8, 1965-1974.

74. Girardet M, Jacotot B, Mendy F, et al. (1977) Effects of edible oils on blood and arterial lipids in rats after one year's balanced normolipidic diet. $J$ Med 8, 261-278.

75. Nydahl M, Gustafsson IB, Ohrvall M, et al. (1994) Similar serum lipoprotein cholesterol concentrations in healthy subjects on diets enriched with rapeseed and with sunflower oil. Eur J Clin Nutr 48, 128-137.

76. Lambert EV, Goedecke JH, Bluett K, et al. (2007) Conjugated linoleic acid versus high-oleic acid sunflower oil: effects on energy metabolism, glucose tolerance, blood lipids, appetite and body composition in regularly exercising individuals. Br J Nutr 97, 1001-1011.

77. Eder E, Wacker M \& Wanek P (2008) Lipid peroxidationrelated 1,N2-propanodeoxyguanosine-DNA adducts induced by endogenously formed 4-hydroxy-2-nonenal in organs of female rats fed diets supplemented with sunflower, rapeseed, olive or coconut oil. Mut Res 654, $101-107$.

78. Moghadasian MH (2008) Advances in dietary enrichment with $n-3$ fatty acids. Crit Rev Food Sci Nutr 48, 402-410.

79. De Caterina R, Endres S, Kristensen SD, et al. (1994) n-3 Fatty acids and renal diseases. Am J Kid Dis 24, 397-415.

80. Priyamvada S, Priyadarshini M, Arivarasu NA, et al. (2008) Studies on the protective effect of dietary fish oil on gentamicin-induced nephrotoxicity and oxidative damage in rat kidney. PLEFA 78, 369-381.

81. Dahl L, Bjorkkjaer T, Graff IE, et al. (2006) Fish - more than just omega 3. Tidsskr Nor Laegeforen 126, 309-311.

82. Conde CMS, Cyrino FZGA, Bottino DA, et al. (2007) Longchain $n$-3 polyunsaturated fatty acids and microvascular reactivity: observation in the hamster cheek pouch. Microvasc Res 73, 237-247.

83. Mozaffarian D, Prineas RJ, Stein PK, et al. (2006) Dietary fish and $n-3$ fatty acid intake and cardiac electrocardiographic parameters in humans. J Am Coll Cardiol 48, 478-484.

84. Theobald HE, Goodall AH, Sattar N, et al. (2007) Low-dose docosahexaenoic acid lowers diastolic blood pressure in middle-aged men and women. J Nutr 137, 973-978.

85. McLennan P, Howe P, Abeywardena M, et al. (1996) The cardiovascular protective role of docosahexaenoic acid. Eur J Pharmacol 300, 83-89.

86. Plourde M \& Cunnane SC (2007) Extremely limited synthesis of long chain polyunsaturates in adults: implications for their dietary essentiality and use as supplements. Appl Physiol Nutr Metab 32, 619-634.

87. Lee JH, O'Keefe JH, Lavie CJ, et al. (2008) Omega-3 fatty acids for cardioprotection. Mayo Clin Proc 83, 324-332.

88. Chiu WC, Wang YC, Chien YW, et al. (2009) Effect of dietary fish oil supplementation on cellular adhesion molecule expression and tissue myeloperoxidase activity in hypercholesterolemic mice with sepsis. J Nutr Biochem 20, 254-260.

89. McLennan PL (1993) Relative effects of dietary saturated, monounsaturated, and polyunsaturated fatty acids on cardiac arrhythmias in rats. Am J Clin Nutr 57, 207-212.

90. Mclennan PL \& Abeywardena MY (2005) Membrane basis for fish oil effects on the heart: linking natural hibernators to prevention of human sudden cardiac death. Membrane Biol 206, 85-102.

91. Nielsen KC \& Owman C (1968) Difference in cardiac adrenergic innervation between hibernators and nonhibernating mammals. Acta Physiol Scand 316, 1-30.

92. Wolowyk MW, Hewlett S, Gordon T, et al. (1990) Smoothmuscle contractility and calcium-channel density in hibernating and nonhibernating animals. Can J Physiol Pharmacol 68, 68-70.

93. Wang W, Schulze C, Suarez-Pinzon W, et al. (2002) Intracellular action of matrix metalloproteinase- 2 accounts for acute myocardial ischemia and reperfusion injury. Circulation 106, 1543-1549.

94. Abdukeyum GG, Owen AJ \& McLennan PL (2008) Dietary $(n-3)$ long-chain polyunsaturated fatty acids inhibit ischemia and reperfusion arrhythmias and infarction in rat heart not enhanced by ischemic preconditioning. J Nutr 138, 1902-1909.

95. Hlavackova M, Neckar J, Jezkova J, et al. (2007) Dietary polyunsaturated fatty acids alter myocardial protein kinase-C expression and affect cardioprotection induced by chronic hypoxia. Exp Biol Med 232, 823-832.

96. Burr ML, Ashfield-Watt PA, Dunstan FD, et al. (2003) Lack of benefit of dietary advice to men with angina: results of a controlled trial. Eur J Clin Nutr 57, 193-200.

97. Leaf A, Albert CM, Josephson M, et al. (2005) Prevention of fatal arrhythmias in high-risk subjects by fish oil $n-3$ fatty acid intake. Circulation 112, 2762-2768.

98. Brouwer IA, Zock PL, Camm AJ, et al. (2006) Effect of fish oil on ventricular tachyarrhythmia and death in patients with implantable cardioverter defibrillators: the study on omega3 fatty acids and ventricular arrhythmia (SOFA) randomized trial. JAMA 295, 2613-2619.

99. Den Ruijter HM, Berecki G, Opthof T, et al. (2007) Pro- and antiarrhythmic properties of a diet rich in fish oil. Cardiovasc Res 73, 316-325.

100. Wilhelm M, Asskali RTF, Kraehner R, et al. (2008) Red blood cell omega-3 fatty acids and the risk of ventricular arrhythmias in patients with heart failure. Am Heart $J \mathbf{1 5 5}$, 971-977.

101. Huikuri HV, Castellanos A \& Meyerburg RJ (2001) Sudden death due to cardiac arrhythmias. $N$ Engl J Med 345, $1473-1482$

102. D'Allesandro ME, Chicco A \& Lombardo YB (2008) Dietary fish oil reverses lipotoxicity, altered glucose metabolism, and $n P K C \epsilon$ translocation in the heart of dyslipemic insulin-resistant rats. Metabol Clin Exp 57, 911-919.

103. He K, Liu K, Daviglus ML, et al. (2008) Intakes of longchain $n-3$ polyunsaturated fatty acids and fish in relation to measurements of subclinical atherosclerosis. Am J Clin Nutr 88, $1111-1118$.

104. De Marco M, De Simone G, Roman MJ, et al. (2009) Cardiovascular and metabolic predictors of progression of prehypertension into hypertension. The Strong Heart Study. Hypertension 54, 974-980.

105. Wilson TA, Nicolosi RJ, Kotyla T, et al. (2005) Different palm oil preparations reduce plasma cholesterol concentrations and aortic cholesterol accumulation compared to coconut oil in hypercholesterolaemic hamsters. $J$ Nutr Biochem 16, 633-640.

106. Nagendran B, Unnithan UR, Choo YM, et al. (2000) Characteristics of red palm oil, $\alpha$-carotene- and vitamin E-rich refined oil for food uses. Food Nutr Bull 2, 189-194.

107. Sundram K, Sambanthamurthi R \& Tan YA (2003) Palm fruit chemistry. Asia Pac J Clin Nutr 12, 355-362.

108. Ong ASH \& Goh SH (2002) Palm oil: a healthful and costeffective dietary component. Food Nutr Bull 23, 11-22.

109. Ooi CK (1999) Minor components of palm oil. PORIM Bull 38, 29-32.

110. Lehninger AL, Nelson DL \& Cox MM (1993) In Principles of Biochemistry, 2nd ed., pp. 259-262. New York: Worth Publishers. 
111. Ping BTY (2006) Palm carotenoids profile as a quality control tool for palm carotene producers: introducing an improvised method by HPLC-photodiode array and a $\mathrm{C}_{30}$ column. J Oil Palm Res 18, 253-259.

112. Steiner M \& Anatasi J (1975) Vitamin E and platelet aggregation. J Clin Invest 57, 732-737.

113. Chan AC \& Leith MK (1981) Decreased prostacyclin synthesis in vitamin E deficient rabbit aorta. Am J Clin Nutr 34, 2341-2347.

114. Helub BJ, Sicilia I \& Mahadevappa VG (1989) Effect of tocotrienol derivatives on collagen and ADP-induced plasma platelet aggregation. Abstracts, PORUM International Palm Oil Development Conference, 5-9 September, Kuala Lumpur, N 9.

115. Qureshi AA, Qureshi N, Weight JJK, et al. (1991) Lowering of serum cholesterol in hypercholesterolaemic humans by tocotrienols (palmvitee). Am J Clin Nutr 53, 1021S-1026S.

116. Pearce BC, Parker RA, Deason ME, et al. (1992) Hypocholesterolaemic activity of synthetic and natural tocotrienols. J Med Chem 35, 3595-3606.

117. Serbinova E, Khavaja S, Catudioc J, et al. (1992) Palm oil vitamin $\mathrm{E}$ protects against ischaemia/reperfusion injury in the isolated perfused Langendorff heart. Nutr Res 12, 989S-1009S

118. Goh SH, Choo YM \& Ong ASH (1985) Minor constituents of palm oil. J Am Oil Chem Soc 62, 237-240.

119. Lietz G, Henry CJ, Mulokozi G, et al. (2001) Comparison of the effects of supplemental red palm oil and sunflower oil on maternal vitamin A status. Am J Clin Nutr 74, 501-509.

120. Van Stuijvenberg ME, Dhansay MA, Lombard CJ, et al. (2001) The effect of a biscuit with red palm oil as a source of $\beta$-carotene on the vitamin A status of primary school children: a comparison with $\beta$-carotene from a synthetic source in a randomized controlled trial. Eur J Clin Nutr $\mathbf{5 5}$ $657-662$

121. Radhika MS, Bhaskaram P, Balakrishna N, et al. (2003) Red palm oil supplementation: a feasible diet-based approach to improve the vitamin A status of pregnant woman and their infants. Food Nutr Bull 24, 208-217.

122. Hornstra G (1988) Dietary lipids and cardiovascular disease: effects of palm oil. Oleagineux 43, 75-81.

123. Ng TKW, Hassan K, Lim JB, et al. (1991) Non hypercholesterolemic effects of a palm-oil diet in Malaysian volunteers. Am J Clin Nutr 53, 1015S-1020S.

124. Qureshi AA, Bradlow BA, Brace L, et al. (1995) Response of hypercholesterolaemic subjects to administration of tocotrienols. Lipids 30, 1171-1177.

125. Sundram K, Anisah I, Hayes KC, et al. (1997) Trans (elaidic) fatty acids adversely impact lipoprotein profiles relative to specific saturated fatty acids in humans. $J$ Nutr 127, 514S-520S

126. Chandrasekharan N (1999) Changing concepts in lipid nutrition in health and nutrition. Med J Malaysia 54, 408-428.

127. Kritchevsky D, Tepper SA \& Kuksis A (1999) Effects of palm oil, randomized palm oil and red palm oil on experimental atherosclerosis. FASEB J 13, A213.

128. Khosla P \& Sundram K (1997) Effects of dietary palmitic and oleic acids on lipoprotein cholesterol. Am J Clin Nutr 65, 170-171.
129. Renaud SC, Ruf JC \& Petithory D (1995) The positional distribution of fatty acids in palm oil and lard influences their biologic effects in rats. J Nutr 125, 229-237.

130. Khor HT, Chieng DY \& Ong KK (1995) Tocotrienols inhibit HMG-CoA reductase activity in the guinea pig. Nutr Res $\mathbf{1 5}$ 537-544.

131. Zhang J, Wang CR, Xue AN, et al. (2003) Effects of red palm oil on serum lipids and plasma carotenoids level in Chinese male adults. Biomed Environ Sci 16, 348-354.

132. Salinas N, Márquez M, Sutil R, et al. (2008) Effect of partially refined palm oil in lipid profile in rats. Invest Clin 49, 5-16.

133. Abeywardena MY \& Charnock JS (1995) Dietary lipid modification of myocardial eicosanoids following ischaemia and reperfusion in the rat. Lipids 30, 1151-1156.

134. Narang D, Sood S, Thomas MK, et al. (2004) Effect of dietary palm oil on oxidative stress associated with ischaemic-reperfusion injury in isolated rat heart. $B M C$ Pharmacol 4, 29.

135. Esterhuyse AJ, Du Toit EF \& Van Rooyen J (2005) Dietary red palm oil supplementation protects against the consequences of global ischaemia in the isolated perfused rat heart. Asia Pac J Clin Nutr 14, 340-347.

136. Esterhuyse AJ, Du Toit EF, Benade AJS, et al. (2005) Dietary red palm oil improves reperfusion cardiac function in the isolated perfused rat heart of animals fed a high cholesterol diet. PLEFA 72, 153-161.

137. Bester DJ, Van Rooyen J, Du Toit EF, et al. (2006) Red palm oil protects against the consequences of oxidative stress when supplemented with dislipidaemic diets. Med Technol SA 20, 3-10.

138. Engelbrecht AM, Esterhuyse AJ, Du Toit EF, et al. (2006) p38-MAPK and PKB/Akt, possible role players in red palm oil-induced protection of the isolated perfused rat heart. J Nutr Biochem 17, 265-271.

139. Esterhuyse JS, Van Rooyen J, Strijdom H, et al. (2006) Proposed mechanisms for red palm oil induced cardioprotection in a model of hyperlipidaemia in the rat. PLEFA $\mathbf{7 5}$, $375-384$

140. Kruger MJ, Engelbrecht AM, Esterhuyse AJ, et al. (2007) Dietary red palm oil reduces ischaemia-reperfusion injury in rats fed a hypercholesterolaemic diet. $\mathrm{Br} J$ Nutr 97, $653-660$

141. Van Rooyen J, Esterhuyse AJ, Engelbrecht AM, et al (2008) Health benefits of a natural carotenoid rich oil: a proposed mechanism of protection against ischaemia/ reperfusion injury. Asia Pac J Clin Nutr 17, Suppl. 1, 316-319.

142. Engelbrecht AM, Odendaal L, Du Toit EF, et al. (2009) The effect of dietary red palm oil on the functional recovery of the ischaemic/reperfused rat heart: the involvement of the PI3-kinase signalling pathway. Lipids Health Dis 8, 18.

143. Du Toit EF, Meiring J \& Opie LH (2001) Relation of cyclic nucleotide ratios to ischaemic and reperfusion injury in nitric oxide-donor treated rat hearts. $J$ Cardiovasc Pharmacol 38, 529-538.

144. Khairallah RJ, Khairallah M, Gélinas R, et al. (2008) Cyclic GMP signalling in cardiomyocytes modulates fatty acid trafficking and prevents triglyceride accumulation. $\mathrm{J} \mathrm{Mol}$ Cell Cardiol 45, 230-239. 